\title{
KEY FACTORS IN THE MEDIA PROPAGATION EFFECT OF ECOTOURISM
}

\author{
WU, Y. H. ${ }^{1}-$ KUO, Y. H. ${ }^{2}-$ YANG, C. Y. ${ }^{3 *}$ \\ ${ }^{I}$ Department of Industrial Engineering and Management, Cheng Shiu University, \\ No. 840, Chengcing Rd., Niaosong Dist., Kaohsiung 83347, Taiwan ROC \\ ${ }^{2}$ Department of Business Administration, Cheng Shiu University, Taiwan ROC \\ No. 840, Chengcing Rd., Niaosong Dist., Kaohsiung 83347, Taiwan ROC \\ ${ }^{3}$ Department of Hospitality and M.I.C.E Marketing Management, National \\ Kaohsiung University of Hospitality and Tourism, No. 1, Songhe Rd., Xiaogang Dist., Kaohsiung \\ 81271, Taiwan ROC \\ *Corresponding author \\ e-mail: chihyun@mail.nkuht.edu.tw \\ (Received $12^{\text {th }}$ Aug 2016; accepted $15^{\text {th }}$ Nov 2016)
}

\begin{abstract}
With the constant progress of Internet and communication technology, various emerging technologies and market applications constructed on network environments are progressed to influence people's reading habits and information collection methods. After being satisfied the material life, the citizens present abundant economic ability and time on the leisure life and the participation in leisure and recreation activity in past years. Rural ecological environments and historical and cultural monuments are the major recreation activity for public tourism, attracting people who live in urban jungles visiting the countryside for landscape appreciation and local culture experience. Users of the official website of Fujian Tourism Bureau, as the research subjects, are surveyed through online questionnaire. Total 1000 copies of questionnaire are distributed and 683 valid copies are retrieved, with the retrieval rate $68 \%$. According to the overall weight of evaluation indicators for the factors in the media propagation effect of ecotourism, the research results show top five indicators, among twelve ones, of customized services, development and network externality application, catering to the market taste and creativity, novelty and exploratory experience, and hardware development of devices. Suggestions, based on the research results, are proposed in this study, expecting to influence the ecological conservation issue on the public life through mass media as well as to promote ecotourism.
\end{abstract}

Keywords: digital reading,consumer, delphi, industrial environment, technology

\section{Background and motivation}

With the changing technologies, the public can easily accept information and depend more on electronic media. Besides, people appear fewer concerns on public affairs so that more easily accessed information becomes the major source of information. Print news media are daily issued and largely published, while the public news reading habit has gradually changed from traditional paper-based media to electronic media which allows real-time browsing and combines various functions. In the world wide web (WWW) environment, electronic media websites, as a type of information-provided service industry, need to strive for users' clicks and satisfy user demands. Information searchers, after using electronic media websites, would compare the websites with personal expectation as the reference of satisfaction with electronic media websites. 
After being satisfied the material life, people have abundant economic ability and time to stress on leisure life and participate in leisure and recreation activity. "Natural landscape appreciation activity" is the highest recreation activity when the public engage in tourism, followed by "culture experiencing activity". To cope with above demands, rural ecological environments and historical and cultural monuments in many touring spots are utilized for attracting people who live in urban jungles to leave cities for landscape appreciation and local culture experience. Ecotourism is a type of tourism covering nature conservation and leisure development. Under the concept of ecotourism, the tourism resources, with careful planning and management, could be maintained for the sustainable tourism activity. In comparison with mass tourism, Wong (2011) regarded ecotourism as the activity containing the objectives of nature conservation and recreation development. Factors in the media propagation effect of ecotourism are therefore discussed in this study, expecting to have the public easily understand the correlation between ecology, biodiversity, and the life through the process of transferring and transforming difficult ecology and biodiversity theories so as to achieve the promotion and communication effect. Besides, it allows the public applying and shaping ecological conservation issues, influences the ecological conservation issue on the public life through mass media, and promotes ecotourism.

\section{Literature review}

\section{Electronic media}

The source of Internet revolution was constantly decreasing costs for computer storage and network bandwidth (Ho, 2012). News and information, through the rapid news and information storing, revising, and delivering on the Internet, therefore are no longer restricted by time units, as for traditional newspaper, television, and broadcast, present both linear and non-linear reading models, and allow readers easily producing news with texts, photos, or audio/video by sharing them on social networking sites (Bian and Forsythe, 2012). The constant development of Internet, technology, and communication technology has the type and classification of online publishing become diversified and has publishing through the Internet become a trend. Especially, after the emergence of world wide web (WWW) in the 90s, applying browsers to collect information, different from the use of E-mail and Telnet in the past, has become a part of daily life of Internet users (Ju and Sirkin, 2010).

Strand (2010) mentioned that news media contained not only newspapers, but also print media, broadcast, and television as the providers of news and information. Whatever combined above characteristics of news media and was presented with digital methods could be regarded as electronic media (Hall, 2012). Electronic media are defined in this study as being collected and edited by specific units or organizations, utilizing world wide web (WWW) for updating daily news information with websites, and applying web pages to issue or actively deliver information to offer readers' reading and browsing with reading methods different from traditional ones. Lee and Cho (2010) revealed different characteristics between electronic media and traditional newspapers, as electronic news provided multiple choices of reading methods for promoting readers' initiative. Yang (2011) indicated that, comparing to fixed layouts of traditional newspapers on which news and information could not be moved, readers, in the 
electronic news reading process, could select interested information for editing personal-style news reports through the Internet hyperlink to satisfy the distinct demands for news reports. In other words, electronic newspapers offer readers with larger freedom and initiative to choose news reports (Gervautz and Schmalstieg, 2012). Electronic media are the news media industry as well as the digital publishing industry. Marshall et al. (2011) mentioned that reading documents, network information, or articles through digital media, such as digital reading devices of computers or smartphones, were the digital reading activity. Electronic media present news and information on different media devices, with electronic form, for readers' reading.

\section{Digital reading}

Sun (2010) revealed that paper was the uniform reading device for reading behavior in the past, because there was no other object to replace it. Nevertheless, there were various types of equipment in the digital reading time suitable for readers' reading habits. Some people were used to reading with large-screen computers, while some other users would read through mobile phones or tablet computers (Zarrella, 2011). In the era when paper was the media device, different publications, although issued with paper forms, showed different types. For example, books were issued with book form, while calligraphy, painting, and newspapers were issued with paper form. Although different types were created to cope with various reading and publishing characteristics, they were still paper-based devices (Green and Oort, 2013). Kao (2011) also considered that a digital-type reading interface was considered as digital reading no matter how the original source of content or a new presentation type was either the document scanned from paper to become an image or directly edited in a computer. Digital reading activity is changed by new types of media and devices, but the reading communication and interaction, such as listening, speaking, reading, and writing, are not changed. As a result, the reading model is further explained, aiming at the characteristics of digital reading (Jacucci et al., 2010), as (1)traditional publishing model being challenged, (2)changes of readers' reading models, (3)interactive experiences in reading, and (4)far-reaching reading activity.

Müller et al. (2012) pointed out the key factors of media combination, digital reading characteristics, and digital reading devices in readers' electronic media reading processes.

(1) Media combination: According to research on electronic media, electronic media websites were presented with different multimedia combinations and website functions like texts, pictures, photos, sound, animation, or films (Lewis and Porter, 2010).

(2) Digital reading characteristics: Stafford and Grimes (2012) argued, through the research report of use conditions of news websites from ARO online survey, that electronic media readers concerned mostly about the characteristics of news instantaneity, operating simplicity and speed, classification and structure, picture and text size, smoothness, and aesthetic.

(3) Digital reading devices: Based on E-book survey in Taiwan area from Insight Xplorer in October, 2010, personal computers (PC), Note-book, tablet computers (Tablet PC), smartphones, and e-book readers were top 5 mostly used digital reading devices with Internet access capability (Tim, 2012). 


\section{Key success factor}

Jeong et al. (2012) considered that Key Success Factor (KSF) supported or threatened the achievement of company goals and was even the primary factors in the existence of a company. Leidecker and Hinrichs and Carpendale (2011) indicated that KSF should cover three analytic levels of macro environment, industrial environment, and enterprise environment, where opportunities and threats were found out from the macro and industrial environment and the competitor dimension for strategy validation and environment analyses. The advantages and disadvantages of an enterprise were further evaluated to analyze the resources and evaluate the distribution of limited resources on KSF so as to plan successful dominant strategies. KSF therefore is defined in this study as the prior consideration in industry analyses and the most important control variable in management. Mantha (2011) mentioned that the search for key success factors in the industry could examine an enterprise's resources and analyze the immediate opportunities and threats of the industry so as to set differentiation strategies which could not be followed or imitated by business operation or competitors. KSF presents four characteristics. (1) It dynamically adjusts with the changes of market, time, region, corporate body, industry, or product life cycle and needs to clearly understand any changes in environments. (2) It presents prospection, considers the future development of industry, and focuses not only on short-term objectives but also medium- and long-term trend. (3) Managers should confirm KSFs in the industry as the reference for decision-making and concentrate the enterprise resources on the most important field to reduce resource misallocation and develop competitive advantages of the enterprise. (4) Capital, manpower, and time are limited resources of an enterprise that managers should effectively apply such resources to the key successful field of the enterprise.

Shin et al. (2011) pointed out the key success factors in television program makers, including 1.necessary factors of core technology, company positioning, courage to innovate, targeted object, leader style, frequent change, brand image, and entry timing and 2.adequate factors of channel expansion, product attribute, casting ability, integration of production and marketing, low cost, agency of major brokerage business, promotional activity, and foreign partners. Kim and Lee (2011) explained the key factors in the third generation $(3 \mathrm{G})$ of mobile telecommunications service market as following. 1. Internal effects of an enterprise contain powerful application services, stability, security and network management ability of telecommunication systems, mobile terminal equipment satisfying consumer demands, payment distribution between telecommunication system businesses and other businesses, offer of personalized and customized 3G services, service content aiming at enterprise users, and mobile terminal supply speed satisfying market demands. 2. External influence on an enterprise covers complete governmental regulations and restrictions, diversified synergy of telecommunication enterprises, and external application of networks. Stever (2011) regarded the key success factors in websites with audio/video contents as value content orientation, long-term and rich audio/video sources, dealing with channel conflict with sub-layout management, reduction of streaming costs, understanding users to enhance the payment willingness, digital right management, market expansion and customer basis, and effectively sticking users. 


\section{Research design and methodology}

\section{Delphi method}

In this study, AHP dimensions and criteria are established based on Delphi Method. Delphi Method, also named expert investigation, is a decision-making approach by separately sending problems to experts, through mails, for the opinions, organizing the comprehensive opinions, which are returned to experts with predicted problems for further opinions when the experts revise the original opinions according to comprehensive ones, and running the steps for several times to gradually acquire consistent prediction results.

According to the system program of Delphi Method, opinions are anonymously given. In other words, no discussion or lateral linkage appears between experts, but merely the relationship with the researchers. Through several runs of questionnaire survey, the prediction results are acquired with repeated inquiry, deduction, revision, and organization of consistent expert opinions. Such a method presents broad representativeness and is considered more reliable.

\section{Establishment of evaluation indicators}

The questionnaire in this study is sent to experts in various fields through emails. The first-time expert feedback is organized the factors in the media propagation effect of ecotourism, then the factors with similar properties are classified and sent back to the experts for further opinions. The method is proceeded for several times through emails. Finally, an expert conference is held to gather all experts to set the factors in the media propagation effect of ecotourism, including industrial environment dimension, technology dimension, content dimension, and consumer dimension. Such key factors as the AHP dimensions and the classification as the criterion are used for establishing the AHP questionnaire. The evaluation factors, revised through Delphi Method, in this study are shown as below.

(1) Industrial environment dimension (local culture and living habits, excellent talents for industries, complete policy act)

(2) Technology dimension (hardware development of devices, selection of system specifications, development and network externality application)

(3) Content dimension (catering to the market taste and creativity, rich audio/video sources)

(4) Consumer dimension (targeted group, novelty and exploratory experience, user-friendly operation of platform interface, customized services)

\section{Research subject}

Users of the official website of Fujian Tourism Bureau are collected through online questionnaire as the research samples in this study. A total of 1000 copies of questionnaire are distributed and 683 valid copies are retrieved, with the retrieval rate $68 \%$. Fujian Tourism Bureau, the affiliated institution of the provincial government in charge of tourism, presents the major duties of coordinating provincial tourism development, making provincial tourism development policies, plans, and standard, developing provincial domestic tourism and inbound and outbound tourism market development strategies and the organization and practice, organizing provincial tourism 
resource census, planning, development, and relative protection, undertaking the order of tourism markets, monitoring and managing the quality of service, protecting legal rights of tourism consumers and operators, promoting provincial tourism and international exchange and cooperation, and making, organizing, and practicing tourism talent planning.

\section{Data analysis result}

After completing all hierarchic weights, indicators in different levels are distributed according to the relative importance to show the importance of indicators in the entire evaluation system, and the overall weight of factors in the media propagation effect of ecotourism is shown in Table 1.

Table 1. Overall weights of factors in Taiwanese catering businesses investing in China

\begin{tabular}{|c|c|c|c|c|c|}
\hline Dimension & $\begin{array}{c}\text { Hierarchy } 2 \\
\text { weight }\end{array}$ & $\begin{array}{c}\text { Hierarchy } 2 \\
\text { sequence }\end{array}$ & Indicator & $\begin{array}{l}\text { Overall } \\
\text { weight }\end{array}$ & $\begin{array}{r}\text { Overall } \\
\text { sequence }\end{array}$ \\
\hline \multirow{3}{*}{$\begin{array}{l}\text { Industrial } \\
\text { environment } \\
\text { dimension }\end{array}$} & \multirow{3}{*}{0.140} & \multirow{3}{*}{4} & $\begin{array}{c}\text { Local culture } \\
\text { and living habits }\end{array}$ & 0.042 & 12 \\
\hline & & & $\begin{array}{c}\text { Excellent talents } \\
\text { for industries }\end{array}$ & 0.064 & 9 \\
\hline & & & $\begin{array}{l}\text { Complete policy } \\
\text { act }\end{array}$ & 0.052 & 11 \\
\hline \multirow{3}{*}{$\begin{array}{l}\text { Technology } \\
\text { dimension }\end{array}$} & \multirow{3}{*}{0.289} & \multirow{3}{*}{2} & $\begin{array}{c}\text { Hardware } \\
\text { development of } \\
\text { devices }\end{array}$ & 0.087 & 5 \\
\hline & & & $\begin{array}{l}\text { Selection of } \\
\text { system } \\
\text { specification }\end{array}$ & 0.073 & 7 \\
\hline & & & $\begin{array}{c}\text { Development } \\
\text { and network } \\
\text { externality } \\
\text { application }\end{array}$ & 0.126 & 2 \\
\hline \multirow{2}{*}{$\begin{array}{l}\text { Content } \\
\text { dimension }\end{array}$} & \multirow[t]{2}{*}{0.267} & \multirow[t]{2}{*}{3} & $\begin{array}{l}\text { Catering to the } \\
\text { market taste and } \\
\text { creativity }\end{array}$ & 0.102 & 3 \\
\hline & & & $\begin{array}{c}\text { Rich audio/video } \\
\text { sources }\end{array}$ & 0.071 & 8 \\
\hline \multirow{4}{*}{$\begin{array}{l}\text { Consumer } \\
\text { dimension }\end{array}$} & \multirow{4}{*}{0.304} & \multirow{4}{*}{1} & Targeted group & 0.082 & 6 \\
\hline & & & $\begin{array}{l}\text { Novelty and } \\
\text { exploratory } \\
\text { experience }\end{array}$ & 0.093 & 4 \\
\hline & & & $\begin{array}{c}\text { User-friendly } \\
\text { operation of } \\
\text { platform } \\
\text { interface } \\
\end{array}$ & 0.060 & 10 \\
\hline & & & $\begin{array}{l}\text { Customized } \\
\text { services }\end{array}$ & 0.148 & 1 \\
\hline
\end{tabular}




\section{Conclusion}

According to the experimental analysis in this study, the following conclusions are summarized.

"Consumer dimension", weighted 0.304 , is the mostly emphasized dimension in Hierarchy 2, about $30.4 \%$ of overall weight, followed by "technology dimension" (weighted 0.289), "content dimension" (weighted 0.267), and "industrial environment dimension" (weighted 0.140). Such a result reveals that consumer dimension is the mostly emphasized factor in the media propagation effect of ecotourism.

The hierarchic weights of evaluation indicators in Hierarchy 3 are sequenced as below.

1. Evaluation indicators in industrial environment dimension are sequenced excellent talents for industries, complete policy act, and local culture and living habits.

2. Evaluation indicators in technology dimension are sequenced development and network externality application, hardware development of devices, and selection of system specification.

3. Evaluation indicators in content dimension are sequenced catering to the market taste and creativity and rich audio/video sources.

4. Evaluation indicators in consumer dimension are sequenced customized services, novelty and exploratory experience, targeted group, and user-friendly operation of platform interface.

By organizing the overall weight of evaluation indicators for the factors in the media propagation effect of ecotourism, customized services, development and network externality application, catering to the market taste and creativity, novelty and exploratory experience, and hardware development of devices, among 12 ones, are top 5 evaluation indicators.

\section{Suggestion}

Based on the research conclusion, the following suggestions are proposed to provide definite guidance and direction for the media propagation effect of ecotourism.

1. The government should actively promote the production-broadcasting separation policy and assist ecotourism industry in establishing a common transmission platform. The frequency distribution should be licensed from the aspects of digital convergence and encouragement of ecotourism development, and the rules for ecotourism businesses operating media should be established. The management regulations for content channels should be rapidly clarified, and both social security and stimulation of ecotourism development should be taken into account for establishing the free-competition market mechanism.

2. In addition to the value, ecotourism businesses should actively integrate and coordinate the establishment of operating platforms, expand the cooperation in the industry, popularize the terminal equipment, and establish the business model. Ecotourism businesses should master the once-for-all steps for the mobile television service, including technology, user test, and business model integration. Successful media communication services should cover four stages of good infrastructure, well-placed hardware development of devices, mastery of catering to the market taste and creativity as well as novelty and rich exploratory contents, and offer of 
customized personal services.

3. In addition to video content services, ecotourism businesses should create multiple and multiplex media innovation through data transmission technology, cut in from different value-added experiences, and create brand-new experience value for consumers. Moreover, ecotourism businesses should master key success factors, provide development and network externality application, and integrate unique services to establish the threshold which the competitors could hardly follow or imitate.

\section{REFERENCE}

[1] Bian, Q., Forsythe, S. (2012): Purchase intention for luxury brands: a crosscultural comparison. - Journal of Business Research 65: 1443-1451.

[2] Gervautz, M., Schmalstieg, D. (2012): Anywhere Interfaces Using Handheld Augmented Reality. - IEEE Computer Society 45: 26-31.

[3] Green, K., Oort, M. (2013): We wear no pants: selling the crisis of masculinityin the 2010 super bowl commercials. - Sign 38: 695-719.

[4] Hall, R. (2012): The brilliance of this TNT advertisement is immeasurable. http://blog.newsok.com/lcr/2012/04/18/the-brilliance-of-this-tnt-advertisement-is-immeas urable/

[5] Hinrichs, U., Carpendale, S. (2011): Gestures in the wild: studying multi-touch gesture sequences on interactive tabletop exhibits. - CHI '11 Proceedings of the SIGCHI Conference on Human Factors in Computing Systems, 3023-3032.

[6] Ho, M. (2012): Coca-Cola Magic Machine. http://www.trendhunter.com/trends/coca-cola-magic-machine

[7] Jacucci, G., Morrison, A., R., Gabriela T., Kleimola, J., Peltonen, P., Parisi, L., Laitinen, T. (2010): Worlds of information: designing for engagement at a public multi-touch display. - CHI '10 Proceedings of the SIGCHI Conference on Human Factors in Computing Systems, 2267-2276.

[8] Jeong, Y., Tran, H., Zhao, X. (2012): How much is too much? The collective impact of repetition and position in multi-segment sports broadcast. - Journal of Advertising Research 52: 87-101. DOI: 10.2501/JAR-52-1-087-101.

[9] Ju, W., Sirkin, D. (2010): Animate objects: how physical motion encourages public interaction. - PERSUASIVE'10 Proceedings of the 5th international conference on Persuasive Technology, 40-51.

[10] Kao, D. T. (2011): Message sidedness in advertising: The moderating roles of need for cognition and time pressure in persuasion - Scandinavian Journal of Psychology 52: 329-340.

[11] Kim, Y., Lee, H. (2011): Customer satisfaction using low cost carriers. - Tourism Management 32: 235-243.

[12] Lee, S. Y., Cho, Y. S. (2010): Do web uses care about banner Ads anymore? The effects of frequency and clutter in web advertising. - Journal of promotion management 16: 288-302.

[13] Lewis, B., Porter, L. (2010): In-game advertising effects: examining player perceptions of advertising schema congruity in a massively multiplayer online role-playing game. Journal of Interactive Advertising 10: 46-60.

[14] Mantha, C. (2011): The Lynx Augmented Reality Angels Interactive Ad is Astonishing. http://www.trendhunter.com/trends/lynx-augmented-reality-angels 
[15] Marshall, P., Morris, R., Rogers, Y., Kreitmayer, S., Davies, M. (2011): Rethinking 'multi-user': an in-the-wild study of how groups approach a walk-up-and-use tabletop interface. - CHI '11 Proceedings of the SIGCHI Conference on Human Factors in Computing Systems, 3033-3042.

[16] Müller, J., Walter, R., Bailly, G., Nischt, M., Alt, F. (2012): Looking Glass: A Field Study on Noticing Interactivity of a Shop Window. - CHI '12 Proceedings of the SIGCHI Conference on Human Factors in Computing Systems, 297-306.

[17] Shin, J. K., Park, M. S., Pusan, Y. J. (2011): The effect of the online social network structure characteristic on network involvement and consumer purchasing intention: focus on Korean social promotion site. - The 11th international DSI and the 16th APDSI joint meeting, Taipei, Taiwan.

[18] Stafford, T., Grimes, A. (2012): Memory Enhances the Mere Exposure Effect. Psychology and Marketing 29: 995-1003.

[19] Stever, G. (2011): Celebrity worship: Critiquing a construct. - Journal of Applied Social Psychology 41: 27-35.

[20] Strand, M. H. (2010): The mere exposure effect and in-game advertising. MA thesis. California State University, Sacramento.

[21] Sun, T. (2010): Antecedents and consequences of parasocial interaction with sport athletes and identification with sport teams. - Journal of Sport Behavior 33: 194-217.

[22] Tim, C. (2012): Facebook Edge Rank 101 (Get Users Like Viddy and Socialcam): Understanding How Facebook Determines What Gets Shown to Your Fans and Users on Their Newsfeed. Retrieved Jan 21, 2013 from the World Wide Web: http://tempofeng.posterous.com/facebook-by-postrocket

[23] Wong, E. (2011): Utilising Augmented Reality to create a Brand Interaction Application on Mobile Devices. Dissertation. University of Dublin.

[24] Yang, C. C. (2011): The effects of social influence on blog advertising use. - Intercultural Communication Studies 3: 131-147.

[25] Zarrella, D. (2011): Infographic: 5 Questions and Answers about Facebook Marketing. http://danzarrella.com/infographic-5-questions-and-answers-about-facebook-marketing.ht $\mathrm{ml} \#$ 